\section{Prostate-specific antigen testing and opportunistic prostate cancer screening - informed consent}

This is a comprehensive and wellresearched project on the uptake and access of prostate cancer screening. ${ }^{1}$ The authors correctly characterise the transition into a 'post-trial world' as the trend of prostate screening research is moving away from prostate-specific antigen (PSA) testing. However, at the time of writing the PSA test remains the primary screening modality for prostate cancer available to GPs.

For me, an aspect of PSA screening that still raises confusion for clinicians and patients is what constitutes informed consent. As mentioned in the article, current National Institute for Health and Care Excellence guidance suggests men may opt in to screening through shared decision making with their GP. The authors defined opportunistic PSA testing as testing performed on individuals without urinary symptoms. I am curious about the authors' views on how to communicate information on opportunistic PSA testing to men in the primary care setting. There is mention in the article that the status quo is informal, with testing based on clinical suspicion and risk factors. However, as shown by the data, PSA testing uptake is subject to significant variation based on demographic factors.

As far as I am aware there is no standardised process informing men of the opt-in nature of PSA testing. Furthermore, there is an ethical dilemma over whether practices should proactively inform men of the option for PSA testing. If an informed, shared decision-making approach is best practice, should all men beyond a specified age be informed of opt-in PSA screening? On the other hand, it could be argued that a proactive approach to shared decision making is simply a form of PSA screening with an additional step.

\section{Gavin Gordon,}

F2 Doctor in GP Rotation, East Durham Medical Group.

Email: gavin.gordon3lanhs.net

\section{REFERENCE}

1. Clift AK, Coupland CAC, Hippisley-Cox J. Prostatespecific antigen testing and opportunistic prostate cancer screening: a cohort study in England,
1998-2017. Br J Gen Pract 2021; DOI: https://doi. org/10.3399/bjgp20X713957.

DOI: https://doi.org/10.3399/bjgp21X715373

\section{Two-tiered medicine: the increasing disparity in medical care in the UK}

Independent healthcare providers have long been a core part of the UK health system and both patients and GPs should be reassured by the safety and quality of the services delivered in the independent sector to NHS and privately funded patients.

Currently over $84 \%$ of independent acute hospitals are rated good or outstanding by the Care Quality Commission, which compares favourably with the NHS average, with independent providers scoring highly in both the NHS Family and Friends Test, as well as Patient Reported Outcome Measures (PROMs). Indeed, the latest figures available show that 9 of the top 10 providers under PROMs scores for primary hip and knee replacements are from the independent sector.

Dr Dawson is right to acknowledge the importance of transparency in the health service and the need for both NHS and independent providers to work together to provide safe, seamless care for patients - particularly in light of the Paterson case. Indeed, in his report into this last year, the Bishop of Norwich made clear that a 'whole-systems solution' will be needed to minimise the chances of any similar cases happening again. ${ }^{2}$ The independent sector, for its part, has already taken important steps to further strengthen and build upon the medical governance systems already in place, notably with the launch of the "Medical Practitioners Assurance Framework' in 2019, led by Sir Bruce Keogh, which set out key principles around expected practice for acute independent providers in a number of areas, including: clinical governance structures; patient safety, clinical quality, and continuous improvement; wholepractice appraisal of clinicians; and raising and responding to concerns from staff and patients.

NHS and independent-sector partnerships have really stepped up during COVID-19. Over 2.5 million NHS patients have been treated in independent hospitals alone as part of a historic agreement that ensured vital non-COVID treatment, including highly complex urgent cancer care, could continue during the pandemic - hailed as 'lifesaving' by the Royal College of Surgeons. ${ }^{4}$ And with waiting times for NHS treatment getting ever longer, it's vital that these public/private partnerships continue to ensure that patients can access the safe, high-quality treatment they need.

\section{Howard Freeman,}

Clinical Director, Independent Healthcare Providers Network.

Email: howard.freeman1anhs.net

\section{REFERENCES}

1. Dawson J. Two-tiered medicine: the increasing disparity in medical care in the UK. Br J Gen Pract 2021; DOI: https://doi.org/10.3399/bjgp21X714737.

2. James G. Report of the independent inquiry into the issues raised by Paterson. 2020. https://assets. publishing.service.gov.uk/government/uploads/ system/uploads/attachment_data/file/863211/ issues-raised-by-paterson-independent-inquiryreport-web-accessible.pdf (accessed 12 Mar 2021).

3. Keogh B. The Medical Practitioners Assurance Framework. 2020. https://www.ihpn.org.uk/ resources/regulation/mpaf laccessed $12 \mathrm{Mar}$ 2021).

4. Royal College of Surgeons. Recovery of surgical services during and after COVID-19. 2020. https:// www.rcseng.ac.uk/coronavirus/recovery-ofsurgical-services (accessed 12 Mar 2021).

DOI: https://doi.org/10.3399/bjgp21X715385

\section{Correction}

In the editorial by Tang E, et al, Stroke: time to address cognition, Br J Gen Pract 2021; DOI: https:// doi.org/10.3399/bjgp21X714977; In column 2, under Current care, the first line should be: 'National clinical guidelines recommend that stroke patients have a review 6-months post-stroke.' On line 17 the sentence should be: 'Cognition is not the only consequence poststroke, for example, depressive symptoms can often present many years after the initial stroke, particularly if there is cognitive impairment 6-months post-stroke.' The online version has been corrected. (CBritish Journal of General Practice 2021. 